\title{
O Uso de Textos Polêmicos em Sala de Aula: formação e prática docente
}

\author{
Denise Davila' \\ Renata Junqueira de Souza" \\ The University of Georgia, Athens - Estados Unidos da América \\ "Universidade Estadual Paulista, Presidente Prudente/SP - Brasil
}

RESUMO - O Uso de Textos Polêmicos em Sala de Aula: formação e prática docente. O objetivo deste texto é duplo. Primeiro, analisa como Discursos, formas socialmente aceitas de falar/ouvir e escrever/ler sobre sujeitos em grupos sociais específicos (Gee, 2008), podem influenciar o uso ou a censura a textos polêmicos por docentes em sala de aula. Discute o que as pesquisas têm revelado sobre docentes utilizando em suas aulas o tema da diversidade. A partir de exemplo de livro de literatura sobre a temática do racismo, traz sugestões para que os professores possam conduzir discussões que respeitem a diversidade cultural de seus alunos e propiciem a formação de opiniões críticas, fazendo assim do professor da educação básica um sujeito responsivo.

Palavras-chave: Temas Polêmicos. Censura. Estado da Arte. Formação Docente.

ABSTRACT - Including Diverse Texts in the Classroom: teacher training and practice. The purpose of this article is twofold. First, it examines how Discourses, socially accepted ways of speaking, listening, writing, and reading that illustrate individuals' memberships in specific social groups (Gee, 2008), could influence teachers' use or censorship of polemic text in the classroom. Second, this article presents a review of the research literature about teachers' inclusion of culturally diverse themes in their classrooms. For example, it describes professors' use of children's books about racism with new teachers. It also outlines suggestions for guiding discussions that respect students' heritage, build critical literacy, and support culturally responsive teaching pedagogies.

Keywords: Polemic Themes. Censorship. Review of Literature. Pre Service Courses.

Educação \& Realidade, Porto Alegre, v. 38, n. 4, p. 1207-1220, out./dez. 2013.1207

Disponível em: <http://www.ufrgs.br/edu_realidade> 
O Uso de Textos Polêmicos em Sala de Aula

De forma relevante para as pesquisas sobre temas polêmicos, o estudioso em letramento e linguista social James Paul Gee (2008) propõe que Discursos com $D$ maiúsculo sejam considerados como formas de falar/ouvir e escrever/ler inconscientes e acríticas socialmente aceitas, [...] ligadas com maneiras distintas de agir, interagir, apreciar, sentir, vestir, pensar, acreditar, em/com outras pessoas e vários objetos, ferramentas e tecnologias, a fim de aprovar identidades socialmente reconhecíveis engajadas com atividades específicas. (Gee, 2008, p. 155).

Discursos, que sustentam polêmicas, são naturalmente ideológicos e promovem os valores e pontos de vista do grupo social que representam. Eles dizem respeito à distribuição e aquisição de bens sociais em uma sociedade com dinheiro, poder e status, e assim definem quem participa e quem fica marginalizado desses grupos sociais. Consequentemente, Discursos dominantes levam a bens sociais e os membros desses grupos são geralmente proficientes em tais Discursos (Gee, 2008, p. 161).

\section{Discurso Dominante e Censura}

Nos Estados Unidos, a censura de materiais de ensino acontece e é mostrada por meio da Associação Americana de Bibliotecas em uma publicação anual que apresenta os livros infantis frequentemente rejeitados. No Brasil, a censura também é evidente e, embora não haja uma instituição que traga isso à tona, episódios sobre o veto às aquisições de livros infantis são amplamente divulgados pela mídia. Enquanto alguns livros podem não ser formalmente recusados, na sala de aula os professores escolhem e selecionam que tipos de textos e materiais usar com seus alunos, baseados em suas crenças políticas e noções de quais são seus papéis no sistema educacional. A maneira como os docentes privilegiam, excluem, e/ou modificam textos legitima a leitura literária. Esses textos utilizados no espaço escolar são aceitos como apropriados e assim concordam com o Discurso do grupo dominante (Taxel, 1994). Diante de tal perspectiva, Freire; Macedo (1987) afirmam que a censura pode ser cúmplice da opressão dos grupos subordinados. Neste sentido, é importante discutir como professores estabelecem um diálogo entre a escola, o texto literário de tema polêmico e a aceitação desse tipo de material.

\section{Literatura Infantil e Temas Polêmicos}

Podemos dizer que a preocupação com questões referentes ao letramento é algo relativamente recente, que começa a tomar forma a partir do final dos anos 1970 nos Estados Unidos e dos anos 1980 no Brasil. Isso acontece, segundo Soares (1998), porque somente no momento em que novas demandas sociais de uso da leitura e da escrita aparecem é que surge a necessidade de um termo para designá-las. Assim, como até meados dos anos 1980 a grande preocupação no Brasil estava voltada para o alto índice de analfabetismo, somente quando na

1208 Educação \& Realidade, Porto Alegre, v. 38, n. 4, p. 1207-1220, out./dez. 2013 Disponível em: <http://www.ufrgs.br/edu_realidade> 
sociedade começa a haver um número maior de pessoas que domina a língua escrita é que se percebe a necessidade de investigar como se dá a inserção desta nas práticas sociais de leitura e escrita. Nesse momento, foi inevitável pensar em como a escola formava ou poderia formar pessoas letradas.

A partir disso, aos professores dos anos iniciais do ensino são colocadas exigências bastante abrangentes quando se trata da formação do aluno letrado e não somente alfabetizado. Além de desenvolver nos alunos do ensino fundamental hábitos de leitura e de usos de textos diversos, os docentes deveriam inserir em suas aulas textos literários, uma vez que, pela literatura, as crianças têm a oportunidade de se tornar leitoras autônomas. Além disso, o caráter humanizador (Candido, 1972) da literatura é capaz de fazer com que elas se identifiquem com o mundo. No entanto, para que o professor possa constituir esse aluno leitor, é necessário que ele mesmo receba uma formação inicial que contemple letramento, letramento literário, leitura, compreensão leitora e literatura. Faz-se imperativo, também, destacar que ele precisa ter condições de transformar aquilo apreendido em seu curso universitário em atividades práticas significativas para seus alunos.

Neste sentido, a literatura faz parte de salas de aula norte-americanas e brasileiras; no entanto, a maneira como tais livros são utilizados é que difere. A diferença, não somente das condições educacionais (formação docente, acesso à literatura antes da escola, qualidade dos materiais literários e das bibliotecas escolares), mas da História desses dois países, coloca hoje a literatura no centro das discussões sobre a sala de aula. Por conseguinte, pesquisas indicam o uso dos textos literários como pretextos para o ensino do currículo tanto nos Estados Unidos como no Brasil.

O que nos interessa aqui, inicialmente, é verificar como professores utilizam os textos literários sobre temas polêmicos em suas instituições escolares. Discutir temas polêmicos é um desafio, pois, de acordo com Azevedo (1999), embora tais eventos como a diferença, a morte, a loucura, a violência doméstica, entre outros, façam parte de nossa realidade e nos deparemos com eles todos os dias, ao ligar a televisão, ao abrir os jornais, como educadores, no entanto, percebemos que os professores do ensino fundamental temem tais assuntos, como se eles estivessem fora da realidade de seus alunos. Assim, aproximar tais temas e discuti-los em sala de aula tem sido parte de pesquisas e de cursos de formação docente. Esse artigo trata de descrever alguns desses estudos e as relações entre professores/alunos, bem como o endereçamento destes assuntos considerados pela crítica especializada como polêmicos. Diante do exposto, pretendemos discutir, a partir do estado da arte, como docentes responderam a cursos de formação continuada e utilizaram a literatura infantil que aborda temas polêmicos. Assim, o que teremos a seguir é uma revisão da produção da crítica especializada sobre tais pesquisas.

Educação \& Realidade, Porto Alegre, v. 38, n. 4, p. 1207-1220, out./dez. 2013.1209 Disponível em: <http://www.ufrgs.br/edu_realidade> 


\section{Identidade do Professor e Censura}

As percepções dos professores acerca de sua função no sistema educacional poderiam influenciar a seleção e rejeição de textos polêmicos para a sala de aula (Beach, 1993), o que frequentemente se reflete nas experiências dos membros de grupos culturais e/ou sociais não dominantes. De um lado, os educadores se atribuem a tarefa de desenvolver uma cultura comum entre os alunos (Giroux; Mclaren, 1987), mas, por outro lado, também têm a função de transformar jovens em adultos que sejam “[...] subversivos, imaginários, liberadores, políticos e pessoalmente libertados, automotivados, críticos, reflexivos e curiosos" (Smagorinski; Jakubiak; Moore, 2008, p. 452-453). As distintas posições ideológicas nas quais os professores vivem podem determinar a qualidade e a quantidade de materiais multiculturais na sala de aula.

Em termos de qualidade, é preciso compreender que os materiais da sala de aula não são ideologicamente inocentes. Os livros infantis, por exemplo, ensinam cultura de maneira implícita (Arizpe, 2009) porque são artefatos culturais das realidades dos autores (Willis; Harris, 1996). Mesmo os livros de imagem são políticos (Apol, 1998; Cai; Bishop, 2003). Os livros de literatura infantil são repletos de mensagens socializadoras, as quais podem reforçar uma sociedade que aceita preconceitos racistas, classistas, sexistas, e de idade advindas do Discurso dominante (Hollindale, 1988; Stephens, 1992).

De acordo com Luke; Freebody (1997), as narrativas são utilizadas para expor certos valores e preconceitos e o não uso da literatura infantil na sala de aula poderia reforçar inadvertidamente nos leitores uma ideologia passiva. De acordo com Hollindale (1988), estes pré-conceitos são os que mais influenciam e "[...] geralmente [...] refletem a integração do escritor em uma sociedade que os aceita (os pré-conceitos) inadvertidamente" (Hollindale, 1988, p. 12). Em outras palavras, o leitor, no contato com tais narrativas, não conseguirá discernir a ideologia dominante, atribuindo o status de normal para tais evidências.

Muitos professores e formadores de professores desejam a autonomia para selecionar os materiais de sala de aula como um meio de facilitar seus objetivos curriculares e promover "[...] valores corretos ou apropriados” em seus alunos (Luke; Cooke; Luke, 1986, p. 209). Consequentemente, a literatura que esses docentes selecionam para a leitura no contexto escolar está propensa a corresponder a suas ideologias passivas no que diz respeito a questões sociais, políticas e morais.

Interessados nas concepções dos professores sobre livros apropriados para crianças do ensino fundamental, Luke; Cooke; Luke (1986) entrevistaram 54 professores de Queensland, Austrália, com o objetivo de identificar os livros infantis de que eles gostavam, para, posteriormente, verificar se tais livros beneficiariam os alunos. A análise das respostas dos docentes revelou preconceito racial e de gênero, particularmente entre os entrevistados que tinham pouca experiência com

1210 Educação \& Realidade, Porto Alegre, v. 38, n. 4, p. 1207-1220, out./dez. 2013. Disponível em: <http://www.ufrgs.br/edu_realidade> 
crianças. Muitos selecionaram livros de que eles gostavam quando crianças, considerando-os benéficos para seus alunos. A partir das conclusões da pesquisa, os autores defendem o oferecimento de cursos de formação de professores para trabalhar com textos que "[...] direcionem explicitamente a questão do conteúdo ideológico da literatura infantil [...] e incluam discussões concretas de sexo, raça, e os estereótipos das classes sociais" (Luke; Cooke; Luke, 1986, p. 216-217).

Jipson; Paley (1991) estudaram a escolha de textos feita por 55 professores do ensino fundamental nos Estados Unidos e observaram preconceito racial e de gênero. A investigação norte-americana revelou que os textos selecionados refletiam "[...] uma multiplicidade de fatores curriculares, pessoais, estéticos, sociais e ideológicos - todos os quais disputam a atenção do professor" (Jipson; Paley, 1991, p. 157) e serviam para presentificar os conteúdos das disciplinas.

A trajetória dessas pesquisas nos faz questionar a formação docente, o papel da mediação em sala de aula e, consequentemente, a formação ou não de leitores/professores críticos.

\section{Letramento Crítico dos Professores do Ensino Fundamental}

Esta parte do artigo dedica-se a examinar como formadores de professores têm usado práticas de letramento crítico para ajudar alunos e educadores a superar a censura e ler a literatura infantil com olhos críticos. Sintetizam-se os dados sobre o ensino da literatura infantil na formação e no desenvolvimento de programas de ensino acerca de dois temas principais: o desenvolvimento de leitores críticos e o formato das discussões com alunos em sala de aula.

A seção seguinte primeiramente revisa a literatura no que diz respeito ao engajamento dos professores com a literatura infantil sobre temas polêmicos nos contextos de desenvolvimento profissional.

A literatura infantil que se relaciona com as experiências de grupos sociais e culturais não dominantes tem sido usada na formação docente e em programas de desenvolvimento profissional, a fim de ajudar professores a se tornarem educadores multiculturais que sejam tanto praticantes de letramento crítico quanto culturalmente responsivo-competentes ${ }^{1}$ (Apol; Sakuma; Reynolds; Rop, 2003). Como aponta Hade (1997), "Multiculturalismo envolve reforma [...] Precisamos ensinar leitura adequadamente. Presunções desafiadoras acerca de raça, classe e gênero devem estar no núcleo de uma educação multicultural [...]" (Hade, 1997, p. 252). Como um movimento de reforma, a formação multicultural não somente aponta para revisões curriculares, mas defende uma mudança institucional e sistêmica na educação, garantindo as mesmas oportunidades de aprendizagem para todos os alunos, independentemente da raça, gênero, cultura, classe social ou língua (Banks; Banks, 2010).

Educação \& Realidade, Porto Alegre, v. 38, n. 4, p. 1207-1220, out./dez. 2013.1211 Disponível em: <http://www.ufrgs.br/edu_realidade> 
Diante do exposto, leitores críticos ou praticantes de letramento crítico, como caracterizado por Lewison; Flint; Van Sluys (2002), examinam os textos, posicionam-se e enfatizam algumas vozes em detrimento de outras; apreciam perspectivas múltiplas e escutam outros pontos de vista; percebem como a linguagem pode ser empregada para manter ou desestabilizar estruturas de poder e permite igualmente ser interpretada como uma fonte cultural. Defensores do letramento crítico como McLaughlin; DeVoogd (2004) propõem uma abordagem pedagógica para educadores em duas fases:

a) Inicialmente, os professores devem certificar-se de que seus alunos possuem o conhecimento contextual social, cultural e/ou histórico necessário para ler criticamente um texto específico;

b) a seguir, os docentes constroem a aprendizagem do aluno por meio de uma sequência de práticas guiadas, tais como: (1) descrever o que significa ser um leitor crítico; (2) demonstrar o exercício da leitura crítica a partir da discussão do texto, da exposição do pensamento em voz alta; (3) guiar a prática do aluno fazendo perguntas críticas como Que pontos de vista predominam e que pontos de vista ficam marginalizadas ou inexistentes neste texto?; (4) organizar um tempo para que os alunos possam praticar a leitura crítica independentemente, e (5) trabalhar com pequenos grupos de alunos para refletir sobre o processo. Uma abordagem como esta poderia ser empregada com professores em um curso de formação em serviço e também serve como um modelo de trabalho com crianças do ensino básico.

Professores culturalmente responsivo-competentes, como descritos por Ladson-Billings (2001); Villegas; Lucas (2002), compreendem o papel da cultura na educação, aprendem sobre a vida de seus alunos, apoiam-se em uma metodologia que constrói experiências, culturas locais e globais nos estudantes, e assumem a responsabilidade de tornar a escola um lugar mais confortável para cada criança.

Em síntese, professores que são tanto leitores críticos quanto educadores culturalmente responsivos aprovam a análise crítica de textos literários. Para Botelho; Rudman, tal análise "[...] reconhece que toda literatura é um produto histórico-cultural e revela como as relações de poder de classe, raça e gênero trabalham juntos em textos e imagens e, consequentemente, na sociedade" (Botelho; Rudman, 2009, p. 1).

Alguns pesquisadores defendem que docentes aprendam e exerçam práticas de letramento crítico a fim de facilitar o multiculturalismo, mediante o uso de literatura infantil com temas polêmicos em sala de aula (Fu; Fang; Lamme, 2003; Hade, 1997). Neste sentido, os próprios professores devem ser críticos, como será desenvolvido na próxima seção.

1212 Educação \& Realidade, Porto Alegre, v. 38, n. 4, p. 1207-1220, out./dez. 2013. Disponível em: <http://www.ufrgs.br/edu_realidade> 


\section{Professores como Leitores Críticos}

Para os alunos, o trabalho do professor é ajudá-los a desenvolver “[...] metaconsciência e metalinguagem" (Comber, 2001, p. 1) a fim de auxiliá-los a interrogar não somente os textos, mas também problemas sociais da escola e da vida. Assim, o primeiro passo para ajudar as crianças no desenvolvimento de práticas no letramento crítico é auxiliar seus próprios professores a se tornarem leitores críticos (Apol; Sakuma; Reyonlds; Rop, 2003).

Infelizmente, cursos de formação continuada com temas polêmicos, capazes de ampliar o pensamento crítico e as discussões de gênero, raça, entre outros, não fazem parte constante de tais atividades formativas (Harris, 1993). Na verdade, formadores de professores precisam reconhecer que muitos docentes têm experiência limitada em ler de forma crítica (Ketter; Lewis, 2001; Schmidt; Armstrong; Everett, 2007).

Para vários estudiosos, as estratégias - antes, durante e depois do ato de ler - podem formar leitores críticos (Apol; Sakuma; Reynolds; Rop, 2003). Entre tais atividades estão: a atribuição de significados através de artes visuais (Baskwill, 2008), as dramatizações (Graff, 2010), as leituras escolares (Lowry; Sabis-Burns, 2007) e as interpretações a partir de textos escritos e/ou respostas orais. Para esses pesquisadores, os professores devem ter uma formação crítica, mas não se pode olvidar de colocá-los em contato com textos de literatura infantil capazes de motivar boas discussões em sala de aula, bem como orientá-los na escolha de tais livros. A seguir, a partir dessas pesquisas, discutimos leitura escolar e algumas experiências em sala de aula.

\section{Atividades e Práticas Escolares}

Dentre os pesquisadores que conduziram cursos de desenvolvimento profissional ou ensino de literatura infantil, alguns incorporaram em suas grades curriculares artigos escolares sobre letramento crítico, multiculturalismo e temas polêmicos para ajudar os docentes/ alunos a se tornarem leitores críticos.

Em nossa revisão de literatura, Apol et al. (2003) relatam o uso de atividades escritas e orais. Os autores estabeleceram duas perguntas chave para ajudar os professores/alunos na discussão de livros infantis com tema polêmico: "Sobre o que esse livro te fez pensar? Você já teve experiências parecidas com essa? De que forma?" (Apol et al., 2003, p. 242).

Nesta mesma direção, com intuito de facilitar que os professores considerassem suas perspectivas pedagógicas e curriculares, Escamilla; Nathenson-Meja (2003, p. 124) perguntaram: "Você usaria esse livro infantil (de tema polêmico) em sua sala de aula? Por quê? Por que não?"; “Como você utilizaria esse livro para ensinar sobre cultura e diversidade?”. Para estimular os docentes nesse tipo de prática, os pro-

Educação \& Realidade, Porto Alegre, v. 38, n. 4, p. 1207-1220, out./dez. 2013. 1213 Disponível em: <http://www.ufrgs.br/edu_realidade> 
O Uso de Textos Polêmicos em Sala de Aula

fessores-pesquisadores solicitaram que os educadores refletissem sobre: "Como as pessoas que não são membros da cultura corrente são representadas no texto?" (Montero; Robertson, 2006, p. 29). Finalmente, Baskwill (2008) pediu que os educadores pensassem sobre quem são o público-alvo e o leitor subentendido do texto; fundindo esses conceitos pode-se imaginar um leitor ideal.

Outra atividade descrita diz respeito à função dos paratextos neste tipo de discussão. De modo congruente, Apol; Sakuma; Reynolds; Rop (2003) incentivaram os professores a refletirem sobre de que forma os paratextos influenciam os leitores. Esse tipo de atividade traz à tona um olhar mais aprofundado para a capa do livro, os textos das orelhas e da quarta capa, bem como para as ilustrações que podem conferir veracidade ao contexto histórico da narrativa. Perguntas sobre os paratextos fornecem um ponto de partida para os professores avaliarem criticamente os alunos e iniciarem a leitura do texto literário.

Outra atividade mencionada por Baswill (2008) diz respeito a desenhos feitos depois da discussão do texto literário. O autor garante que exercícios envolvendo a visualização ajudam o leitor a organizar seu pensamento, a processar criticamente suas ideias sobre o texto e, por conseguinte, a compreender as diferentes perspectivas de outros docentes/alunos. Neste sentido, Rosenblatt (1985, p. 105) afirma: "Criticismo deveria fazer da transação estética o ponto de partida de uma relação transacional mais ampla entre leitor crítico e texto". Em outros termos, as respostas pessoais dos professores e seu entendimento do texto fornecem um ponto de partida para desenvolver a consciência crítica.

As discussões orais fizeram parte de todas as atividades descritas em nossa revisão de literatura. Os professores pesquisadores trabalharam com diálogos guiados e abertos em sala de aula. Em grupos, os docentes/alunos responderam à literatura. Essas conversas forneceram elementos para examinar problemas de injustiça, racismo, privilégio e poder. Na educação multicultural, dialogar sobre o texto é tão importante quanto ler o texto (Rice, 2005), porque o diálogo é "[...] uma ação inicial para crítica de si mesmo e da sociedade e pode levar a ações mais complexas como discussões desafiadoras sobre injustiças sociais antidemocráticas" (Bercaw; Collins, 2007, p. 31). Para alguns dos pesquisadores, o modelo de discussão em grupos menores defende uma sala de aula "[...] não autoritária em que os alunos são convidados a construir conhecimento compartilhando suas próprias perspectivas e sentimentos" (Singer; Smith, 2003, p. 19) e um espaço semiprivado para que os alunos possam expressar opiniões que poderiam ser rejeitadas na presença do professor.

Sintetizando, o trabalho com textos literários sobre temas polêmicos deve conduzir atividades em sala de aula que chamem atenção dos alunos, desde a capa, passando pelos paratextos, em discussões abertas ou orientadas por questões chave. O importante é que o docen-

1214 Educação \& Realidade, Porto Alegre, v. 38, n. 4, p. 1207-1220, out./dez. 2013. Disponível em: <http://www.ufrgs.br/edu_realidade> 
te se dispa dos preconceitos e saiba gerir atividades que formem alunos críticos, que os façam pensar. Para tanto, além do uso dos textos literários, o professor poderá trazer para a sala de aula, textos informativos sobre o assunto (polêmico) a fim de ampliar o repertório dos discentes e realmente construir conhecimentos a respeito do tema. Neste sentido, expomos como exemplo de tais sugestões o trabalho com o livro O Ônibus de Rosa, de Fabrizio Silei.

\section{A Segregação Racial em Sala de Aula}

O livro de Silei conta a história de um senhor que leva o neto para conhecer o Museu Ford, em Detroit. O avô quer mostrar ao menino um velho ônibus em exposição, dentro do qual ele testemunhou uma das cenas mais extraordinárias de sua vida. Esse é o pretexto para o avô rememorar a história da segregação racial no sul dos Estados Unidos. Sentado novamente ali, onde esteve em 1955, emociona-se ao contar a história de Rosa Parks, uma mulher negra como eles, que desafiou a ordem preestabelecida quando se recusou a ceder seu assento a um homem branco.

Antes de os leitores conhecerem a história, numa tentativa de estabelecer relações entre o texto icônico e o texto verbal, o professor pode pedir para que as crianças descrevam a capa de O Ônibus de Rosa. A seguir, pode questionar o paratexto desse livro, na quarta capa, que diz "Há sempre um ônibus que passa na vida de cada um de nós. Fique de olhos abertos: não vá perder o seu” (Silei, 2012, s. p.).

Tanto as ilustrações da capa (uma senhora negra de óculos entrando num ônibus), quanto o paratexto não evidenciam a história de Rosa Parks e a luta pela igualdade social. O professor pode questionar a capa tentando fazer com que seus alunos infiram quem é a mulher, em que momento se passa a história que será lida, onde a narrativa toma lugar, entre outras.

O professor pode levar os discentes a pensarem no que significa ônibus da vida. E a preocupação em não perder esse ônibus, o que seria? Só depois de discutir e ouvir as respostas dos alunos, o professor irá pedir para que eles leiam o texto. Ao final da leitura, o docente pode sugerir a leitura de um texto informativo sobre a segregação racial da década de 50 para que os leitores consigam compreender melhor a história narrada pelo avô de Ben e o marco histórico do ato de Rosa Parks. Segundo Montero; Robertson (2006), ler o texto informativo facilita a compreensão do texto literário e auxilia o leitor na atribuição de significados críticos, além de oferecer contrapontos às discussões que tendem a ocorrer.

O paratexto pode ser retomado e fará maior sentido após a leitura e discussão do livro, pois não perder o ônibus da vida terá novas significações para leitores do Ensino Fundamental.

Educação \& Realidade, Porto Alegre, v. 38, n. 4, p. 1207-1220, out./dez. 2013.1215 Disponível em: <http://www.ufrgs.br/edu_realidade> 
Discutir em pequenos grupos ou com a sala de aula assuntos tabu sobre diversidade e injustiça pode fornecer elementos para a formação do leitor crítico. Tal atividade facilita a autorreflexão e a compreensão do ponto de vista do outro (Bercaw; Collins, 2007), bem como ajuda a interrogar as ideias dos alunos acerca de textos multiculturais, de temas polêmicos, com o intuito de evitar a censura (Wollman-Bonilla, 1998); também auxilia os discentes a aprender e conversar sobre livros multiculturais, a fim de desenvolver o letramento crítico (Mathis, 2001). Alternativamente, alguns estudiosos ainda sugerem que os leitores sejam expostos a textos e/ou experiências pessoais para perceberem os valores socioculturais embebidos na história (Apol; Sakuma; Reynolds; Rop, 2003; Smith, 2002; Wollman-Bonilla, 1998). Nesta abordagem, a criança mostra para o professor como ler criticamente.

Se por um lado essas atividades podem ajudar a formação do leitor crítico, por outro, a má condução das discussões pode arruinar tal possibilidade. A revisão da literatura mostrou dois grupos de professores/ alunos: um que propiciou tipos de resposta à literatura, especificamente para discutir a literatura infantil sobre temas polêmicos e leituras não escolares, e outro que aligeirou as discussões e utilizou o tema como pretexto para o ensino de determinado conteúdo.

Se tomarmos O Ônibus de Rosa como exemplo para esse segundo grupo de docentes, poderíamos inferir que eles utilizariam o texto de Silei para ensinar a história dos Estados Unidos em momento de segregação racial e a trajetória dos direitos civis dos negros norte-americanos.

Ao descrever a estrutura das conversas, Schmidt; Armstrong; Everett (2007) lembram que "[...] as discussões frequentemente começaram com rápidas respostas estéticas à literatura e mudaram quase imediatamente para atividades que pudessem ser utilizadas com o livro literário na sala de aula" (Schmidt; Armstrong; Everett, 2007, p. 51). Uma razão para esta rápida transação de resposta pessoal à discussão de uso na sala de aula é que os professores têm o hábito de privilegiar questões práticas que poderiam auxiliá-los no ensino dos conteúdos do currículo escolar. Este tipo de atividade, segundo os autores (Schmidt; Armstrong; Everett, 2007), distancia os leitores dos problemas de diversidade e injustiça social em textos multiculturais.

Os pesquisadores, entretanto, reconhecem que, para tais professores - os que usam a literatura como pretexto, a discussão é um ponto de partida para que uma mudança ocorra: a mudança que levará à construção do leitor crítico.

\section{Conclusão}

Se partirmos da prerrogativa de que a grande maioria dos professores não é leitor crítico e que tem dificuldade de oferecer a seus alunos uma educação multicultural, vimos o emprego de uma variedade de atividades para auxiliar tais docentes a lerem criticamente e aplica-

1216 Educação \& Realidade, Porto Alegre, v. 38, n. 4, p. 1207-1220, out./dez. 2013 Disponível em: <http://www.ufrgs.br/edu_realidade> 
rem atividades com textos polêmicos em sala de aula. A maioria dessas atividades propõe discussões orais e escritas preparadas com questões comuns. A familiaridade e o conforto dos professores em ler textos mediante olhares pessoais levantaram algumas discussões (Gee, 2008).

Os pesquisadores afirmaram que, sem levar os professores a confrontarem ideologias dominantes de raça, gênero, cultura e igualdade por meio de perguntas explícitas e outras estratégias de leitura, será difícil, para alguns deles, incorporarem atividades com textos polêmicos em sala de aula.

A forma como este tipo de texto é organizado exerce um efeito profundo no leitor em relação ao modo de se ver o mundo. Ler também está relacionado a expectativas, experiências e conhecimentos prévios que diferem entre os leitores.

Assim, em termos de metodologia pedagógica, os pesquisadores recomendam que os formadores de docentes:

- forneçam oportunidades amplas em programas de educação continuada ou em serviço para que professores leiam literatura infantil sobre temas polêmicos (Lowry; Sabis-Burns, 2007; Mathis, 2001);

- ajudem os professores a interrogar seus próprios critérios de seleção de literatura infantil (Schmidt; Armstrong; Everett, 2007; Wollman-Bonilla, 1998);

- certifiquem-se se os professores têm o conhecimento cultural necessário para se engajarem criticamente com um texto infantil multicultural (Escamilla; Nathenson-Mejia, 2003);

- defendam que os docentes continuem desenvolvendo suas identidades como leitores críticos e educadores culturalmente responsivos por meio de literatura infantil sobre temas polêmicos (Apol; Sakuma; Reynolds; Rop, 2003; Escamilla; Nathenson-Mejia, 2003; Fu; Fang; Lamme, 2003).

Esta revisão de literatura examinou as maneiras com que professores respondem à literatura infantil sobre temas polêmicos e como formadores de professores usam essa literatura em seus cursos para auxiliar esses docentes a se tornarem leitores críticos e educadores culturalmente responsivos.

Neste sentido, o trabalho com o texto literário exige interação entre leitor e texto e especulações sobre o seu significado, propiciando a apreensão de informações importantes. Exige o estabelecimento de relações entre conhecimentos prévios e experiências de vida, bem como a reflexão sobre fatos sociais. Se o professor levar todos estes aspectos em conta na escolha do livro infantil fará uma grande diferença e caminhará rumo à formação do leitor crítico.

Recebido em 26 de março de 2013

Educação \& Realidade, Porto Alegre, v. 38, n. 4, p. 1207-1220, out./dez. 2013.1217 Disponível em: <http://www.ufrgs.br/edu_realidade> 
O Uso de Textos Polêmicos em Sala de Aula

\section{Nota}

1 Entende-se por professor responsivo competente aquele que entende e aprecia as diferenças culturais vindas de seus alunos. Emprega metodologias de ensino que valorizam as experiências discentes e fazem da sala de aula um espaço interativo e dinâmico.

\section{Referências}

APOL, Laura. "But what does this have to do with kids?" Literary theory and children's literature in the teacher education classroom. Journal of Children's Literature, Roanoke, v. 24, n. 2, p. 32-46, 1998.

APOL, Laura; SAKUMA, Aki; REYNOLDS, Tracy; ROP, Sheri. "When can we make paper cranes?" Examining pre-service teachers' resistance to critical readings of historical fiction. Journal of Literacy Research, New York, v. 34, 2003, p. $429-464$.

ARIZPE, Evelyn. Sharing visual experiences of a new culture: immigrant children's responses to Picturebooks and other visual texts. In: EVANS, J. (Org.). Talking Beyond the Page. London: Routledge, 2009. P. 134-151.

AZEVEDO, Ricardo. Livros didáticos e livros de literatura: chega de confusão! Presença Pedagógica, Belo Horizonte, v. 5, n. 25, jan./fev. 1999.

BANKS, James; BANKS, Cherry. Multicultural Education: issues and perspectives. $7^{\text {th }}$ ed. Hoboken, NJ: Wiley, 2010.

BASKWILL, Jane. Exploring teacher attitudes toward multicultural literature through the arts. In: TAYLOR, G.; HINTON, K.; MOORE, L. (Org.). Teaching multicultural literature to help children understand ethnic diversity. Lewiston: The Edwin Mellen Press, 2008. P. 3-14.

BEACH, Richard. Teachers' Introduction to Reader-response Theories. Urbana, IL: National Council of Teachers of English, 1993.

BERCAW, Lynne; COLLINS, Angelo. The discussion filter: culturally relevant children's literature in the teacher education classroom. Teaching \& Learning, Charlotte, NC, v. 22, n. 1, p. 22-33, 2007.

BOTELHO, Maria; RUDMAN, Masha. Critical Multicultural Analysis of Children's literature: mirrors, windows, and doors. New York: Routledge, 2009.

CAI, Mingshui; BISHOP, R. Sims. Multicultural literature for children: toward a clarification of the concept. In: DYSON, A. H.; GENISHI, C. (Org.). The Need for Story: cultural diversity in classroom and community. Urbana, IL: National Council of Teachers of English, 2003. p. 57-71.

CANDIDO, Antonio. A literatura e a formação do homem. Ciência e Cultura, São Paulo, SP, v. 24, n. 9, p. 803-809, set. 1972.

COMBER, Barbara. Negotiating critical literacies. School Talk, National Council of Teachers of English, v. 6, n. 3, p. 12-29, 2001.

ESCAMILLA, Kathy; NATHENSON-MEJIA, S. Preparing culturally responsive teachers: using latino children's literature in teacher education. Equity \& Excellence in Education, v. n. 36, p. 238-248, 2003.

FREIRE, Paulo; MACEDO, Donaldo. A dialogue: culture, language, and race. In: LEISTYNA, P.; WOODRUM, A.; SHERBLOM, S. (Org.). Breaking Free: the transformative power of critical pedagogy. Cambridge, MA: Harvard Educational Review, 1987. P. 199-228.

FU, Danling; FANG, Zhihui; LAMME, Linda. The trivialization and misuse of multicultural literature: issues of representation and communication. In: FOX,

1218 Educação \& Realidade, Porto Alegre, v. 38, n. 4, p. 1207-1220, out./dez. 2013 Disponível em: <http://www.ufrgs.br/edu_realidade> 
D.; SHORT, K. (Org.). Stories Matter: the complexity of cultural authenticity in children's literature. Urbana, IL: National Council of Teachers of English, 2003. P. 284-303.

GEE, James Paul. Social Linguistics and Literacies: ideology in discourses. $3^{\text {rd. }}$ ed. New York: Routledge, 2008.

GIROUX, Henry; MCLAREN, Peter. Teacher education and the politics of engagement: the case for democratic schooling. In: LEISTYNA, P.; WOODRUM, A.; SHERBLOM, S. (Org.). Breaking Free: the transformative power of critical pedagogy. Cambridge, MA: Harvard Educational Review, 1987. P. 301-331.

GRAFF, Jennifer. Countering narratives: teachers' discourse about immigrants and their experiences within the realm of children's and young adult literature. English Teaching: Practice and Critique, Hamilton, NZ, v. 9, n. 3, p. 106-131, 2010.

HADE, Daniel. Reading multiculturally. In: Harris, V. (Org.). Using Multiethnic Literature in the K-8 Classroom. Urbana, IL: National Council of Teachers of English, 1997. P. 233-256.

HARRIS, Violet. Review of against borders: promoting books for a multicultural world. Journal of Reading Behavior, Missouri, v. 26, n.1, p. 117-120, 1993.

HOLLINDALE, Peter. Ideology and the children's book. Signal, Chicago, v. 55, n. 1, p. 3-22, 1988.

JIPSON, Janice; PALEY, Nicholas. The selective traditions in teachers' choices of children's literature: does it exist in the elementary classroom. English Education, Department of Applied Foreign Languages Shih Chien University, v. 23, n. 3, p. 148-159, 1991.

KETTER, Jean; LEWIS, Cynthia. Already reading texts and contexts: multicultural literature in a predominantly white rural community. Theory into Practice, Taylor \& Francis Group, v. 40, p. 175-183, 2001.

LADSON-BILLINGS, Gloria. Toward a theory of culturally relevant pedagogy. American Educational Research Journal, v. 32, n. 3, p. 465-491, 2001.

LEWISON, Mitzi; FLINT, Amy; VAN SLUYS, Katie. Taking on critical literacy: the journey of newcomers and novices. Language Arts, Urbana, v. 75, n. 5, p. 382392, 2002.

LOWERY, Ruth, SABIS-BURNS, Donna. From borders to bridges: Making crosscultural connections through multicultural literature. Multicultural Education, v. 14, n. 4, p. 50-54, 2007.

LUKE, Alan; FREEBODY, Peter. Shaping the social practices of reading. In: MUSPRATT, S.; LUKE, A.; FREEBODY, P. (Org.). Constructing Critical Literacies: teaching and learning textual practice. Cresskill, NJ: Hampton Press, 1997. P. $185-225$.

LUKE, Alan; COOKE, James; LUKE, Carmen. The selective tradition in action: gender bias in student teachers' selection of children's literature. English Education, Urbana, v. 18, n. 4, p. 209-218, 1986.

MATHIS, Janelle. Respond to stories with stories: teachers discuss multicultural children's literature. The Social Studies, Maryland, v. 92, n. 4, p. 155-160, 2001.

MCLAUGHLIN, Maureen; DEVOOGD, Glenn. Critical Literacy: enhancing students' comprehension of text. New York, NY: Scholastic, 2004.

MONTERO, Kristina; ROBERTSON, Joanna. “Teachers can't teach what they don't know": teaching about international and global children's literature to facilitate culturally responsive pedagogy. Journal of Children's Literature, Roanoke, v. 32, n. 2, p. 27-35, 2006.

Educação \& Realidade, Porto Alegre, v. 38, n. 4, p. 1207-1220, out./dez. 2013.1219 Disponível em: <http://www.ufrgs.br/edu_realidade> 
RICE, Peggy. It "ain't” always so: sixth graders' interpretation of Hispanic-American stories with universal themes. Children's Literature in Education, Roanoke, v. 36, n. 4, p. 343-362, 2005.

ROSENBLATT, Louise. The Reader the Text the Poem: the transactional theory of the literary work. Paperback ed. Carbondale: Southern Illinois University Press, 1985.

SCHMIDT, Renita; ARMSTRONG, Linda; EVERETT. Tammy. Teacher resistance to critical conversation: exploring why teachers avoid difficult topics in their classrooms. The NERA Journal, Westerly, v. 43, n. 2, p. 49-55, 2007.

SILEI, Fabrizio. O Ônibus de Rosa. São Paulo: Edições SM, 2012.

SINGER, Judith; SMITH, Sally. The potential of multicultural literature: changing understanding of self and others. Multicultural Perspectives, Lawrence Erlbaum Associates, v. 5, n. 2, p. 17-23, 2003.

SMAGORINSKI, Peter; JAKUBIAK, Cori; MOORE, Cynthia. Student teaching in the contact zone: learning to teach amid multiple interests in a vocational English class. Journal of Teacher Education, American Association of Colleges for Teacher Education, v. 59, p. 442-454, 2008.

SMITH, Sally. "Would I use this book?" White, female education students examine their beliefs about teaching. New Advocate, v. 15, n. 1, p. 57-66, 2002.

SOARES, Magda. Letramento: um tema em três gêneros. Belo Horizonte: CEALE/Autêntica, 1998.

STEPHENS, John. Language and Ideology in Children's Fiction. New York, NY: Longman, 1992.

TAXEL, Joel. Political correctness, cultural politics, and writing for young people. The New Advocate, v. 7, n. 2, p. 93-108, 1994.

VILLEGAS, Ana Maria; LUCAS, Tamara. Preparing culturally responsive teachers: rethinking the curriculum. Journal of Teacher Education, American Association of Colleges for Teacher Education, v. 53, n. 1, p. 20-33, 2002.

WILLIS, Arlette; HARRIS, Violet. Preparing preservice teachers to teach multicultural literature. In: FLOOD, J.; HEATH, S. B.; LAPP, D. (Org.). Handbook of Research on Teaching Literacy Through the Communicative and Visual Arts. New York: Macmillan Library Reference USA, 1996. p. 460-469.

WOLLMAN-BONILLA, Julie. Outrageous viewpoints: teachers' criteria for rejecting works of children's literature. Language Arts, Urbana, v. 75, n. 4, p. 287295, 1998.

Denise Davila é docente do Departamento Language and Literacy Education, da The University of Georgia. Sua pesquisa aborda a diversidade cultural na literatura infantil e na prática de ensino.

E-mail:ddavila@uga.edu

Renata Junqueira de Souza é docente do Departamento de Educação da Universidade Estadual Paulista, campus de Presidente Prudente, e coordenadora do CELLIJ - Centro de Estudos Em Leitura e Literatura Infantil e Juvenil "Maria Betty Coelho Silva".

E-mail: recellij@gmail.com

1220 Educação \& Realidade, Porto Alegre, v. 38, n. 4, p. 1207-1220, out./dez. 2013 Disponível em: <http://www.ufrgs.br/edu_realidade> 